\title{
MS14-P13 | PERIOdIC TREND OF STEREOCHEMICAL ACTIVITY OF LONE ELECTRON PAIRS
}

Murshed, M. Mangir (Universität Bremen, Institut für Anorganische Chemie und Kristallographie, FB Biologie/Chemie, Bremen, GER); Gesing, Thorsten M. (Universität Bremen, Institut für Anorganische Chemie und Kristallographie, FB Biologie/Chemie, Bremen, GER)

In a series of papers, Wang and Liebau [1-3] pointed out that the bond valence sum calculated for a lone electron pair (LEP) cation increases as the cation's coordination environment becomes more distorted. They proposed to associate the geometric distortion of the LEP-coordination as the measures of the stereochemical activity of the LEP using the term eccentricity which we later coined as Wang-Liebau eccentricity (WLE) parameter [4]. Most of the polyhedral distortion indices [5-9] are purely geometric and cannot account for the interaction strength between the atoms. In contrast, the WLE parameter describes the weighted bond length with an exponential function, allowing the strength of a bond to exponentially decrease with increasing bond length. Sampling on crystal information data of $\mathrm{As}-, \mathrm{Se}-, \mathrm{Sn}-, \mathrm{Sb}-, \mathrm{Te}-, \mathrm{Tl}-, \mathrm{Pb}$ - and Bi-oxide coordination, a statistical approach demonstrates that the WLE parameter of the LEP-cations follows a periodic trend.

[1] X. Wang, F. Liebau, Z. Krist. 211 (1996) 437.

[2] X. Wang, F. Liebau, Acta Crystallogra. B 63 (2007) 216.

[3] F. Liebau, X. Wang, W. Liebau, Chem. - A Eur. J. 15 (2009) 2728.

[4] M. Curti, T.M. Gesing, M.M. Murshed et al., Z. Krist. 288 (2013) 629.

[5] K. Robinson, G. V. Gibbs, P.H. Ribbe, Science (80-. ). 172 (1971) 567.

[6] J.M. Gaite, Phys. Chem. Miner. 6 (1980) 9.

[7] W.A. Dollase, Acta Crystallogr. A 30 (1974) 513.

[8] E. Makovicky, T. Balić-Žunić, Acta Crystallogr. Sect. B Struct. Sci. 54 (1998) 766.

[9] P.S. Halasyamani, Chem. Mater. 16 (2004) 3586. 